\title{
Abnormalities of Myeloid Progenitor Cells After "Successful" Bone Marrow Transplantation
}

\author{
Shunong Li, Richard Champlin, John H. Fitchen, and Robert Peter Gale \\ Transplantation Biology Unit and Department of Medicine (Hematology-Oncology Division) University of \\ California at Los Angeles School of Medicine, Los Angeles, California 90024
}

\begin{abstract}
We studied recovery of peripheral blood- and bone marrowderived myeloid progenitor cells (CFU-G,M) in 29 patients who received bone marrow transplants 2 mo to 8.5 yr previously. All patients had normal levels of peripheral blood neutrophils, normal bone marrow cellularity, and a normal myeloid:erythroid ratio. Both peripheral blood- and bone marrow-derived CFU$G, M$ were markedly reduced compared with normal controls and bone marrow donors. $\left[5 \pm 1 / 10^{6}\right.$ vs. $37 \pm 4 / 10^{6}(P<0.001)$ and $23 \pm 5 / 2 \times 10^{5}$ vs. $\left.170 \pm 21 / 2 \times 10^{5}(P<0.001)\right]$. Five patients had no detectable CFU-G,M even when $10^{6}$ bone marrow cells were plated. These abnormalities of $\mathbf{C F U}-\mathbf{G}, \mathbf{M}$ were unrelated to age, sex, diagnosis, conditioning regimen, dose of bone marrow cells transplanted, and presence or absence of graft-vs.-host disease. Patients who received either autotransplants or transplants from identical twins also had decreased or absent CFU-G,M indicating that allogeneic factors and posttransplant immune suppression with methotrexate or corticosteroids were not major determinants of this abnormality. Co-culture of normal or donor peripheral blood or bone marrow mononuclear cells with recipients peripheral blood or bone marrow mononuclear cells, purified $T$ cells, or serum failed to show any evidence of active $\mathrm{CFU}-\mathrm{G}, \mathrm{M}$ suppression. Furthermore, the abnormality of CFU-G,M could not be corrected by the addition of normal syngeneic (donor) hematopoietic cells or serum. Depletion of $\mathrm{T}$-cells from recipient bone marrow by physical techniques resulted in marked increase in CFU-G,M (36 \pm 13 vs. $138 \pm 36 ; P<0.05)$. The abnormality could be reproduced in vitro by readdition of autologous $T$ cells. In contrast to results with $T$ cell depletion by physical techniques, $T$ cell depletion with a monoclonal anti-T antibody (B7) and complement had no effect. These data indicate that most transplant recipients have a marked abnormality in CFU-G,M when these cells are cultured in vitro. In at least some of these patients, the decreased cloning efficiency of CFU-G,M appears to be mediated by a suppressive effect of autologous $T$ cells.
\end{abstract}

Dr. Gale was the Meyerhoff Visiting Scientist at the Weizmann Institute of Science, Rehovot, Israel.

Dr. Fitchen's present address is Medical Research Service, Portland Veterans Administration Medical Center, Portland, OR. Address all correspondence to Dr. Gale, Department of Medicine, Division of Hematology-Oncology, University of California at Los Angeles School of Medicine, The Center for the Health Sciences, Los Angeles, CA 90024.

Received for publication 12 December 1983 and in revised form 27 August 1984.

J. Clin. Invest.

(c) The American Society for Clinical Investigation, Inc. 0021-9738/85/01/0234/08 $\$ 1.00$

Volume 75, January 1985, 234-241

\section{Introduction}

Bone marrow transplantation is increasingly used to treat patients with aplastic anemia, leukemia, and cancer (1). In a typical bone marrow transplant, the recipient receives high doses of drugs and total body radiation. In most instances this treatment is lethal to the recipient's bone marrow cells; the hematopoietic stem cells are irreversibly damaged. It is therefore necessary to rescue the recipient from bone marrow failure by the transplantation of normal hematopoietic stem cells from an homologous leukocytic antigen (HLA)-identical sibling or a genetically identical, monozygotic twin. In some instances cryopreserved autologous bone marrow cells have been used.

The high-dose chemotherapy and radiation used to condition these patients is followed by a rapid decrease in erythrocytes, granulocytes, platelets, and lymphocytes. Pancytopenia persists for 2-3 wk followed by gradual hematologic recovery; blood counts and bone marrow cellularity usually return to normal within 1 to 2 mo. Detailed analyses of gene markers, including sex chromosomes, erythrocyte antigens and polymorphic erythrocyte and leukocyte isoenzymes, indicate that the posttransplant hematopoietic cells are of donor origin.

Despite the restoration of apparently normal hematopoiesis following successful bone marrow transplantation, we questioned whether the pool of hematopoietic stem cells is fully reconstituted and whether these patients have a normal bone marrow reserve. This question was prompted by our observation of decreased hematologic tolerance to cytotoxic drugs in some transplant recipients. We measured granulocyte-macrophage progenitor cells (CFU-G,M) ${ }^{1}$ in blood and bone marrow of 29 patients at 2 mo-7 yr after successful bone marrow transplantation. We found that CFU-G,M were markedly decreased but that this abnormality could be reversed by the removal of $T$ lymphocytes. These data raise questions about the extent of hematopoietic reconstitution after apparently "successful" bone marrow transplantation.

\section{Methods}

Patients. 29 patients who received syngeneic, allogeneic, or autologous bone marrow transplants at University of California at Los Angeles between September 1975 and December 1981 and were alive 2 mo to $8.5 \mathrm{yr}$ after transplantation were selected for study. The clinical details, including diagnosis, source, and dose of the transplanted marrow cells and pretransplant conditioning regimen are summarized in Table I. Median age was $29 \mathrm{yr}$ (range, 17-50 yr). There were 20 males and 9

1. Abbreviations used in this paper: AA, aplastic anemia; ALL, acute lymphoblastic leukemia; AML, acute myelogenous leukemia; BFU-E, erythrocyte burst-forming unit; CFU-G,M, granulocyte-macrophage progenitor cells; CFU-S, hematopoietic stem cells; CML, chronic myelocytic leukemia; CSA, colony-stimulating activity; GVHD, graftvs.-host disease; $M / E$, myeloid/erythroid ratio. 


\begin{tabular}{|c|c|c|c|c|c|c|c|c|}
\hline \multirow[b]{2}{*}{ Recipient } & \multirow[b]{2}{*}{ Age } & \multirow[b]{2}{*}{ Sex } & \multirow[b]{2}{*}{ Diagnosis } & \multicolumn{2}{|c|}{ Donor } & \multirow[b]{2}{*}{ Relationship* } & \multirow[b]{2}{*}{ Conditioning: } & \multirow[b]{2}{*}{ Marrow dose } \\
\hline & & & & Age & Sex & & & \\
\hline & & & & & & & & $\times 10^{8} / \mathrm{kg}$ \\
\hline 013 & 50 & $\mathbf{M}$ & AML & 44 & $\mathbf{M}$ & HLA = Sib & SCARI & 2.8 \\
\hline 059 & 39 & $\mathbf{M}$ & AML & 33 & $\mathbf{M}$ & HLA = Sib & CY-TBI-1 & 3.8 \\
\hline 135 & 29 & $\mathbf{M}$ & AML & 26 & $\mathbf{M}$ & HLA $=$ Sib & CY-TBI-1 & 2.4 \\
\hline 136 & 23 & $\mathbf{F}$ & AML & 23 & $\mathbf{F}$ & Twin & CY-TBI-1 & 2.7 \\
\hline 152 & 25 & $\mathbf{M}$ & AML & 23 & $\mathbf{M}$ & HLA = Sib & CY-TBI-1 & 3.2 \\
\hline 153 & 20 & $\mathbf{M}$ & AML & 19 & $\mathbf{M}$ & HLA = Sib & CY-TBI-1 & 2.2 \\
\hline 170 & 20 & $\mathbf{M}$ & $\mathbf{A A}$ & 19 & $\mathbf{M}$ & HLA $=$ Sib & CY-TBI-2 & 5.4 \\
\hline 173 & 26 & $\mathbf{M}$ & AML & 25 & $\mathbf{M}$ & HLA $=$ Sib & CY-TBI-1 & 3.0 \\
\hline 174 & 26 & $\mathbf{M}$ & AML & 25 & $\mathbf{M}$ & HLA $=$ Sib & CY-TBI-1 & 3.0 \\
\hline 175 & 31 & $\mathbf{F}$ & $\mathbf{A A}$ & 33 & $\mathbf{M}$ & HLA = Sib & CY-TBI-2 & 2.0 \\
\hline 186 & 22 & $\mathbf{F}$ & AML & 24 & $\mathbf{M}$ & HLA = Sib & CY-TBI-1 & 1.3 \\
\hline 208 & 37 & $\mathbf{F}$ & AML & 45 & $\mathbf{F}$ & HLA $=$ Sib & CY-TBI-1 & 3.1 \\
\hline 211 & 24 & $\mathbf{M}$ & $\mathbf{A A}$ & 20 & $\mathbf{M}$ & HLA $=\mathrm{Sib}$ & CY-TBI-2 & 3.4 \\
\hline 217 & 47 & $\mathbf{M}$ & AML & 49 & $\mathbf{M}$ & HLA = Sib & CY-FTBI & 1.5 \\
\hline 221 & 41 & $\mathbf{M}$ & $\mathbf{A A}$ & 32 & $\mathbf{M}$ & HLA $=$ Sib & CY-TBI-2 & 2.5 \\
\hline 230 & 19 & $\mathbf{M}$ & $\mathbf{A A}$ & 20 & $\mathbf{F}$ & HLA = Sib & CY-TBI-2 & 1.6 \\
\hline 232 & 39 & $\mathbf{M}$ & CML & 54 & $\mathbf{M}$ & HLA $=$ Sib & CY-TBI-1 & 2.3 \\
\hline 233 & 22 & $\mathbf{M}$ & $\mathbf{A A}$ & 27 & $\mathbf{M}$ & HLA $=$ Sib & CY-TBI-2 & 2.0 \\
\hline 239 & 39 & $\mathbf{M}$ & $\mathbf{A A}$ & 37 & $\mathbf{M}$ & HLA = Sib & CY-TBI-2 & 2.4 \\
\hline 244 & 17 & $\mathbf{F}$ & AML & 22 & $\mathbf{M}$ & HLA $=$ Sib & TBI (15 Gy) & 2.9 \\
\hline 247 & 35 & $\mathbf{F}$ & CML & 31 & $\mathbf{F}$ & HLA $=\mathbf{S i b}$ & CY-TBI-1 & 1.9 \\
\hline 254 & 23 & $\mathbf{F}$ & ALL & 29 & $\mathbf{M}$ & HLA $=$ Sib & CY-TBI-1 & 3.5 \\
\hline 252 & 25 & $\mathbf{M}$ & ALL & 33 & $\mathbf{M}$ & $\mathrm{HLA}=\mathrm{Sib}$ & TBI (15 Gy) & 3.8 \\
\hline 253 & 22 & $\mathbf{F}$ & CML & 27 & $\mathbf{M}$ & HLA $=$ Sib & CY-TBI-1 & 5.4 \\
\hline 255 & 22 & $\mathbf{F}$ & AML & 42 & $\mathbf{M}$ & HLA $=$ Sib & TBI (13.5 Gy) & 3.0 \\
\hline 9006 & 20 & $\mathbf{M}$ & Testis Ca & - & - & Auto & CY-TBI-VLB-DOX & 0.7 \\
\hline 9016 & 36 & $\mathbf{M}$ & Lymphoma & 36 & $\mathbf{M}$ & Twin & CY-TBI-VLB-DOX & 1.9 \\
\hline 9035 & 29 & $\mathbf{M}$ & Testis $\mathrm{Ca}$ & - & - & Auto & CY-TBI & 4.3 \\
\hline 9036 & 24 & $\mathbf{M}$ & ALL & - & - & Auto & CY-TBI & 2.6 \\
\hline
\end{tabular}

* HLA = Sib, HLA-A, B, C, and D identical sibling; Twin, monozygotic genetically identical twin; Auto, transplant of cryopreserved autologous bone marrow mononuclear cells. ¥CY-TBI-1: cyclophosphamide $(120 \mathrm{mg} / \mathrm{kg})$, total body irradiation (TBI) (10 Gy); CY-TBI-2: cyclophosphamide $(200 \mathrm{mg} / \mathrm{kg})$, TBI (3 Gy); SCARI: 6-thioguanine $\left(3 \mathrm{~g} / \mathrm{m}^{2}\right)$, cytarabine $\left(3 \mathrm{~g} / \mathrm{m}^{2}\right)$, daunorubicin $\left(180 \mathrm{mg} / \mathrm{m}^{2}\right)$, cyclophosphamide $(120 \mathrm{mg} /$ $\mathrm{kg})$, and TBI (10 Gy), CY-TBI-VLB-DOX; cyclophosphamide (150-180 mg/kg), TBI (8 Gy), vinblastine (1 mg/kg), and doxorubicin (120-150 $\mathrm{mg} / \mathrm{m}^{2}$ ).

females. Seven had aplastic anemia (AA). 20 patients had hematologic malignancies including 13 acute myelogenous leukemia (AML), 3 with chronic myelogenous leukemia (CML), 3 with acute lymphoblastic leukemia (ALL), and one with a diffuse mixed lymphocytic-histiocytic lymphoma. Two patients had nonseminomatous testicular tumors. 24 patients received transplants from HLA-A,B,C,D identical siblings. Two patients, one with AML and one with lymphoma received transplants from genetically identical monozygotic twins. Three patients including two with testicular carcinoma and one with ALL received autotransplants.

The 24 allogeneic donors and 2 identical twin donors were all hematologically normal. Median age was 31 yr (range 19-54 yr) 22 were males and 4 females.

Pretransplant conditioning consisted of cyclophosphamide (120$200 \mathrm{mg} / \mathrm{kg}$ ) and total body irradiation (3-10 Gy) (2). Some patients also received high-dose cytarabine, 6-thioguanine, and daunorubicin. Allograft recipients received methotrexate $15 \mathrm{mg} / \mathrm{m}^{2}$ on day 1 posttransplant and $10 \mathrm{mg} / \mathrm{m}^{2}$ on days $3,6,11$, and weekly to day 102 to prevent or modify graft-vs.-host disease (GVHD). Details of transplantation, antibiotics, blood product transfusions, protected environments, and prevention and treatment of GVHD and interstitial pneumonitis have been reported $(4-6)$. Most patients $(18 ; 62 \%)$ were studied at a time when they were no longer receiving methotrexate. Patients receiving myelotoxic drugs (excluding methotrexate) or antibiotics were excluded. In patients studied before day +102 , samples were obtained 5-6 d after the preceding dose of methotrexate. Results in these patients did not differ from those observed in autotransplant or twin transplant recipients (who did not receive methotrexate) or from recipients studied after day 102 (when methotrexate had been discontinued). Some patients were receiving intermittent trimethoprim-sulfamethoxazole and folinic acid up to 6 mo posttransplant for prophylaxis against pneumocystis carinii. Samples from these patients were obtained $\geq 5$ d after the preceding drug dose. No difference was noted in results comparing patients receiving or not receiving trimethoprim-sulfamethoxazole or in patients studied $<$ or $\geq 6$ mo posttransplant. As an additional precaution we studied CFU-G,M in three nontransplant patients receiving equivalent doses of trimethoprim-sulfamethoxazole; all three had normal levels of peripheral blood and bone marrowderived CFU-G,M.

Two patients, one with AML and one with a mixed cell nonHodgkins lymphoma (7), received bone marrow transplants from genetically identical, monozygotic twins. Identity was established by 
similarity of appearance, history of a single placenta, and identity for dermatoglyphics, erythrocyte and leukocyte isoenzymes (8). Both patients were conditioned with cyclophosphamide and total body irradiation. The patient with lymphoma also received high doses of vinblastine and doxorubicin. These patients did not receive methotrexate after transplantation.

Two patients with testicular cancer resistant to conventional chemotherapy, received high doses of vinblastine, doxorubicin, cyclophosphamide, or etoposide with or without total body radiation. This was followed by infusion of autologous cryopreserved bone marrow cells. Details of these patients have been reported (7).

Hematologic determinations. Erythrocyte, leukocyte, and platelet counts were determined by standard techniques using an automated Coulter particle counter (Coulter Electronics, Hialeah, FL). Differential counts of $\geq 200$ cells were performed on Wright's or Giemsa-stained peripheral blood smears on at least three occasions in all patients within 1 mo of the CFU-G,M determination.

Bone marrow cellularity was determined by microscopic assessment of bone marrow biopsies. Cellularity was evaluated by two investigators unfamiliar with the patients' clinical course or peripheral blood cell counts. Differential cell counts were performed on $\geq 200$ cells from bone marrow aspirates and the myeloid/erythroid $(\mathrm{M} / \mathrm{E})$ ratio determined.

Cell preparation. Bone marrow samples were obtained from the posterior iliac crest under local anesthesia and mixed in 1,000 U preservative-free heparin. Bone marrow or peripheral blood mononuclear leukocytes were recovered from the saline, Ficoll-Hypaque interface after density centrifugation (9). Cells were washed, and resuspended in RPMI 1640 medium (Gibco Laboratories, Grand Island, NY) with $20 \%$ fetal calf serum.

$C F U-G, M$ assay. Bone marrow mononuclear cells $\left(2 \times 10^{5}\right.$ cell/ $\mathrm{ml})$ or peripheral blood mononuclear cells $\left(10^{6} / \mathrm{ml}\right)$ were plated in $0.3 \%$ agar in the presence of colony-stimulating activity (CSA) as described (10). CSA was provided either by $10^{6}$ peripheral blood leukocytes in a feeder layer (11) or by the addition to plates of $25 \mu \mathrm{l}$ conditioned medium from a $T$ lymphoblastoid cell line (12). Samples from several patients were tested with both sources of CSA with comparable results; these data were thus combined for analysis. Under these conditions, bone marrow cells from 20 healthy adult volunteers form $170 \pm 21 / 2 \times 10^{5}$ (range, 41-368) CFU-G,M derived colonies and peripheral blood cells form $37 \pm 4 / 10^{6}$ (range, 26-53) CFU-G,M colonies.

In initial experiments using $2 \times 10^{5}$ bone marrow cells/plate, $\mathrm{CFU}$ G,M derived colonies from transplant recipients were undetectable or markedly decreased. Therefore, in subsequent experiments, cells were also plated at a concentration of $10^{6}$ cells/plate. Plates were incubated at $37^{\circ} \mathrm{C}$ in a humidified atmosphere of $5-7.5 \% \mathrm{CO}_{2}$ in air for $10 \mathrm{~d}$ and colonies containing $\geq \mathbf{4 0}$ cells were enumerated under a dissecting microscope.

Co-culture. Co-cultures were performed as follows: Bone marrow mononuclear $\left(2 \times 10^{5}\right)$ or peripheral blood mononuclear cells $\left(10^{6}\right)$ from transplant recipients were co-cultured with an equal number of bone marrow or peripheral blood mononuclear cells from the donor or normal volunteers at $37^{\circ} \mathrm{C} \times 60 \mathrm{~min}$. The cells were then plated as described. In some experiments, $\mathrm{E}$ rosette-forming cells were depleted from recipient or normal bone marrow samples (before plating). These autologous $T$ cells were readded to the E-depleted bone marrow cell at ratios of $1: 5,1: 2$, or 1:1 $\left(\mathrm{E}^{+}: \mathrm{E}^{-}\right)$. The reconstituted samples were incubated at $37^{\circ} \mathrm{C}$ for $60 \mathrm{~min}$ and then plated for CFU-G,M. To test the effects of serum on CFU-G,M, $0.1 \mathrm{ml}$ of serum from either the recipient or normals was added to $0.9 \mathrm{ml}$ containing bone marrow or peripheral blood mononuclear cells of the recipient, donor, or normal controls. Cells were incubated at $37^{\circ} \mathrm{C}$ for $60 \mathrm{~min}$ and then plated.

Depletion of $E$ rosette-forming $T$ lymphocytes. Mononuclear cells obtained from bone marrow or peripheral blood were incubated with 5\% neuraminidase-treated sheep erythrocytes suspended in fetal calf serum (13). The cells were then layered on a Ficoll-Hypaque density gradient and centrifuged at $400 \mathrm{~g}$ for $30 \mathrm{~min}$. E rosette negative ( $\left.\mathrm{E}^{-}\right)$ cells were recovered from the interface, washed, and resuspended in
RPMI 1640. To recover $E$ rosette positive cells $\left(E^{+}\right)$devoid of sheep erythrocytes, $9 \mathrm{ml}$ sterilized distilled water was added to the pellet for $10 \mathrm{~s}$; isotonicity was then restored by adding $1 \mathrm{ml}$ of 10 times phosphate-balanced saline (PBS). The cells were twice washed and resuspended in RPMI 1640 medium. Viability was $\geq 90 \%$ in most experiments and was frequently $>95 \%$.

Monoclonal antibody. Mononuclear cells from bone marrow or peripheral blood were incubated with a cytotoxic murine monoclonal antibody, B7, with specificity for the $E^{-}$rosette receptor on $T$ cells $(R$. Billing, personal communication). $10^{7}$ cells $/ \mathrm{ml}$ were mixed with $\mathrm{B} 7$ at a final concentration of $1: 50$ and incubated at $37^{\circ} \mathrm{C}$ for $30 \mathrm{~min}$ in a 16-mm test tube. Normal rabbit serum was added as a source of complement at a final concentration of $1: 6$ and incubated at $37^{\circ} \mathrm{C}$ for $60 \mathrm{~min}$. Aliquots were removed for assessment of $\mathrm{E}^{+}$rosette-forming cells and for immunofluorescence. The residual cells were plated for CFU-G,M without washing. In a typical experiment $<1 \% \mathrm{E}$ rosetteforming cells were detected following B7 treatment and $<2 \%$ reacted with untreated anti-T lymphocyte antibodies Leu 1, Leu 2, Leu 3, by immunofluorescence (14). Treatment with normal rabbit serum alone had no effect on $\mathrm{E}^{+}$rosette formation.

Erythrocyte burst-forming unit (BFU-E) assay. Peripheral blood or bone marrow mononuclear cells were isolated as described. The mononuclear cells were suspended in Iscove's medium (Gibco Laboratories) at a concentration of $3 \times 10^{6} / \mathrm{ml}$. BFU-E were then assayed in the presence of $1 \mathrm{U}$ of human urinary erythropoietin as described (15). Plates were incubated for $14 \mathrm{~d}$ in a $5 \%$ humidified $\mathrm{CO}_{2}$ atmosphere and BFU-E ( 250 cells) were enumerated using an inverted microscope.

Statistical analysis. Results of the transplant patients and controls were compared by the Student's $t$ test. Analysis of trends was performed by the Mann-Whitney test (16).

\section{Results}

Peripheral blood and bone marrow cellularity and myeloid:erythroid ratio of the 29 patients are indicated in Table II. Leukocyte counts were normal in 19 , minimally decreased in 4 , and low in 5 patients. One patient with chronic GVHD and recurrent bacterial infections had a persistently elevated leukocyte count $\left(16.2 \times 10^{9} /\right.$ liter $)$. The percent neutrophils was also normal in most instances, with only four patients with low values. Hemoglobin was normal in 26 patients; 3 patients were anemic with hemoglobin $<10 \mathrm{~g} / \mathrm{dl}$. Eleven patients had thrombocytopenia. Bone marrow cellularity ranged from 25 to $60 \%$ (median $40 \%$ ). M/E ratio ranged from 1:1 to 10:1 (median 2:1). One patient had an increased $M / E$ ratio that was normal on repeat testing.

Tests of bone marrow-derived CFU-G,M were performed on 26 occasions: 22 patients were studied once and 4 patients were studied twice (Table III). Transplant recipients had a mean of $23 \pm 5$ (SEM) CFU-G,M/2 $\times 10^{5}$ cells compared with $170 \pm 21$ in 20 controls $(P<0.001)$. Seven recipients had no detectable CFU-G,M. These individuals were tested a median of 17 mo posttransplant (range, 2-57 mo). One recipient (9006) had no detectable CFU-G,M at 18 mo and a reduced number $\left(29 / 2 \times 10^{5}\right)$ was detected at 25 mo posttransplant. Bone marrow cells from four recipients without detectable CFU-G,M were plated at a higher concentration of $10^{6} /$ plate. In two, low numbers of CFU-G,M (5 and 11/106) were observed; two others still had no detectable CFU-G,M. The seven recipients without CFU-G,M when cells were plated at $2 \times 10^{5} / \mathrm{ml}$ included three with AML, two with aplastic anemia, one with a lymphoma, and one with testicular cancer. Five received allogeneic transplants, one a syngeneic transplant, and one an autotransplant. The latter two patients did not 
Table II. Peripheral Blood and Bone Marrow Analyses*

\begin{tabular}{|c|c|c|c|c|c|c|c|}
\hline Recipient & $\begin{array}{l}\text { Interval } \\
\text { posttransplant }\end{array}$ & Leukocytes & Neutrophils & Hemoglobin & Platelets & $\begin{array}{l}\text { Bone marrow } \\
\text { cellularity }\end{array}$ & Ratio \\
\hline & $m$ & $\times 10^{9} /$ liter & $\%$ & $g / d l$ & $\times 10^{\circ} /$ liter & $\%$ & $M / E$ \\
\hline 013 & 57 & 7.4 & 47 & 13.1 & 218 & 40 & $3: 1$ \\
\hline 013 & 84 & 9.8 & 55 & 14.8 & 244 & 40 & $3: 1$ \\
\hline 059 & 42 & 9.9 & 59 & 12.3 & 295 & 60 & $3: 1$ \\
\hline 135 & 6 & 6.0 & 59 & 13.0 & 260 & 45 & $3.5: 1$ \\
\hline 136 & 15 & 6.6 & 53 & 11.8 & 250 & 40 & $2: 1$ \\
\hline 152 & 6 & 9.6 & 84 & 13.6 & 200 & 30 & $1.5: 1$ \\
\hline 153 & 21 & 16.2 & 55 & 10.5 & 550 & 50 & $2: 1$ \\
\hline 170 & 2 & 6.7 & 85 & 14.9 & 143 & 50 & $1.5: 1$ \\
\hline 170 & 17 & 8.0 & 74 & 14.9 & 210 & 50 & $2.5: 1$ \\
\hline 173 & 2 & 3.4 & 77 & 13.6 & 200 & 30 & $1.5: 1$ \\
\hline 174 & 2 & 4.1 & 47 & 12.0 & 11 & 60 & $1: 1$ \\
\hline 175 & 17 & 8.3 & 34 & 12.0 & 300 & 50 & $2: 1$ \\
\hline 186 & 15 & 8.4 & 63 & 15.1 & 366 & 30 & $1: 1$ \\
\hline 208 & 10 & 6.0 & 58 & 10.0 & 195 & 40 & $2.5: 1$ \\
\hline 211 & 8 & 6.2 & 60 & 13.6 & 55 & 50 & $2: 1$ \\
\hline 217 & 7 & 6.5 & 47 & 11.6 & 161 & 50 & $1.6: 1$ \\
\hline 221 & 6 & 6.8 & 65 & 14.4 & 343 & NT & NT \\
\hline 230 & 5 & 9.3 & 30 & 11.8 & 26 & 40 & $1: 1$ \\
\hline 232 & 2 & 4.3 & 45 & 8.9 & 84 & 25 & $1: 1$ \\
\hline 233 & 12 & 5.3 & 66 & 9.7 & 233 & 60 & $1: 1$ \\
\hline 239 & 8 & 3.6 & NT & 14.7 & 130 & 30 & $1: 1$ \\
\hline 244 & 4 & 4.0 & 57 & 11.5 & 32 & 25 & $1.6: 1$ \\
\hline 247 & 1 & 1.26 & 70 & 12.0 & 37 & 70 & $1.5: 1$ \\
\hline 252 & 1 & 1.8 & 31 & 12.9 & 50 & 30 & $1.3: 1$ \\
\hline 253 & 1 & 2.1 & 47 & 12.3 & 70 & 40 & $2: 1$ \\
\hline 254 & 1 & 3.7 & 55 & 9.7 & 39 & 30 & $2: 1$ \\
\hline 255 & 1 & 2.4 & 89 & 11.5 & 3 & 45 & $1.2: 1$ \\
\hline 9006 & 18 & 9.1 & 69 & 13.9 & 215 & 25 & $10: 1$ \\
\hline 9006 & 43 & 8.8 & 69 & 14.2 & 352 & 50 & $3: 1$ \\
\hline 9016 & 21 & 5.3 & 67 & 12.9 & 241 & 30 & $3: 1$ \\
\hline 9035 & 3 & 5.7 & 65 & 11.7 & 220 & 50 & $2: 1$ \\
\hline 9036 & 14 & 3.3 & 20 & 15.2 & 52 & 40 & $2: 1$ \\
\hline \multirow[t]{2}{*}{ Median } & 8 & 6.6 & 61 & 12.9 & 207 & 40 & $2: 1$ \\
\hline & & $4.5-$ & & & & & \\
\hline Normalsł & - & 11.0 & $45-80$ & $11.5-18$ & $130-360$ & $25-75$ & $1: 1-5: 1$ \\
\hline
\end{tabular}

* NT, not tested. $¥$ Normal values summarized (16).

posttransplant methotrexate. When the seven patients without detectable CFU-G,M were compared with the 22 with detectable but decreased values, no correlation with donor or recipient age, diagnosis, type of donor pretransplant, or posttransplant chemotherapy or time past bone marrow transplantation was evident. Data comparing the frequency of CFU-G,M and

Table III. CFU-GM of Transplant Recipients

\begin{tabular}{|c|c|c|c|c|}
\hline & \multicolumn{2}{|c|}{$\begin{array}{l}\text { Bone marrow } \\
\text { (CFU-GM per } 2 \times 10^{5} \\
\text { cells plated) }\end{array}$} & \multicolumn{2}{|c|}{$\begin{array}{l}\text { Blood (CFU-GM per } 10^{6} \\
\text { cells plated) }\end{array}$} \\
\hline & $n$ & Mean \pm SE (range) & $n$ & Mean \pm SE (range) \\
\hline Recipients & 26 & $23 \pm 5 \quad(0-43)$ & 30 & $5 \pm 1(0-43)$ \\
\hline Controls & 20 & $170 \pm 21(41-368)$ & 5 & $37 \pm 4(26-53)$ \\
\hline
\end{tabular}

interval post transplant are indicated in Fig. 1. Trend analysis failed to demonstrate any significant correlation of CFU-G,M abnormalities with time during the interval studied.

A reduction in peripheral blood CFU-G,M was also noted (Table III). 30 tests were performed in 20 transplant recipients. Mean CFU-G,M was $5 \pm 1 / 10^{6}$ cells plated (range, $0-43$ ). This is significantly lower than that detected in normals and transplant donors, $37 \pm 4 / 10^{6}$ (range, 26-53) $(P<0.001)$. These data are presented graphically in Fig. 1. Again, there was no apparent correlation between interval posttransplant and peripheral blood derived CFU-G,M.

Co-cultures of bone marrow or peripheral blood mononuclear cells from the recipient and normal volunteer were performed on four occasions (Table IV). In all instances the number of CFU-G,M detected was consistent with the arithmetic sum of donor and recipient CFU-G,M. No evidence of an inhibitory effect on normal CFU-G,M or of an ability of 

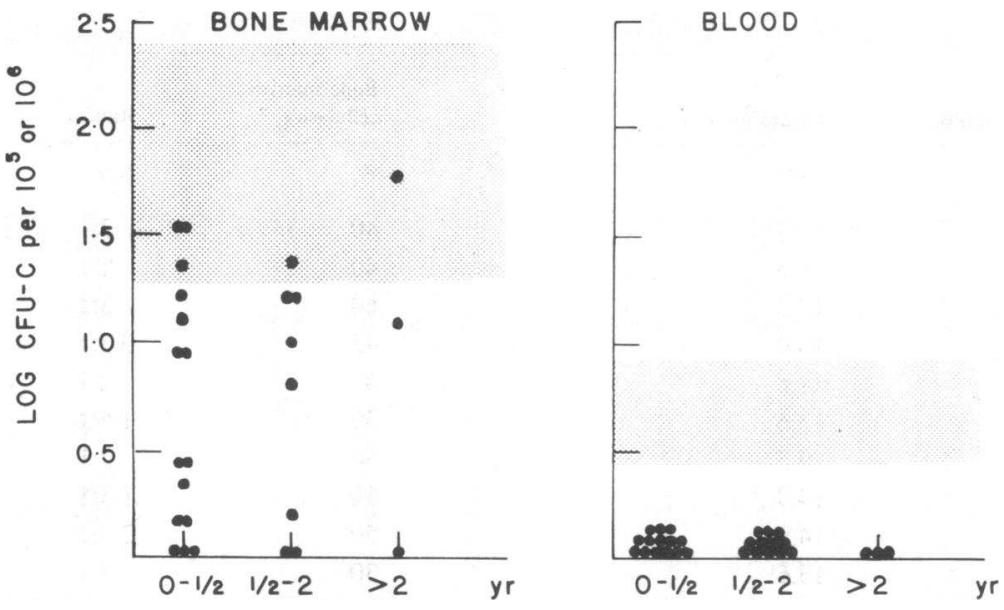

Figure 1. Studies of CFU-G,M as a function of interval after bone marrow transplantation.

normal peripheral blood or bone marrow cells to amplify otherwise undetectable CFU-G,M was observed under these conditions.

In two experiments, bone marrow mononuclear cells from transplant recipients were co-cultured with comparable cells from their donors. In both instances the CFU-G,M observed was reduced from expected values (Table IV).

When serum from transplant recipients was added to peripheral blood mononuclear cells from normal individuals or donors $(n=3)$, no significant increase or decrease in CFUG,M was detected compared with cultures containing autologous serum (data not shown).

To further investigate the cause of decreased CFU-G,M in transplant recipients, we cultured recipient bone marrow or peripheral blood derived mononuclear cells following depletion of autologous $\mathrm{E}^{+}$rosette-forming cells. Removal of $\mathrm{E}^{+}$rosette cells resulted in an increase of bone marrow derived CFUG,M from $36 \pm 13 / 2 \times 10^{5}$ to $138 \pm 36(0.05>P>0.02)$ (Table V). This increase could not be accounted for simply by the removal of cells without CFU-G,M activity since only $15-27 \%$ of the initial bone marrow samples formed $\mathrm{E}^{+}$rosettes. Furthermore, removal of $\mathrm{E}^{+}$rosette-forming cells from controls resulted in only a modest increase in CFU-G,M (170 \pm 21 to $209 \pm 48 / 2 \times 10^{5}$ ). This increase was not significant. Similar studies were also performed using recipient peripheral blood mononuclear cells depleted of $\mathrm{E}^{+}$rosette-forming cells. Again,

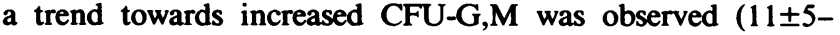
$25 \pm 11 / 10^{6}$ ) but this was not significant.

In the next series of experiments, we studied this inhibitory effect of $\mathrm{E}^{+}$rosette-forming cells from transplant recipients on bone marrow CFU-G,M by readdition of autologous $\mathrm{E}^{+}$rosette-

Table IV. Co-culture of Recipient and Normal Cells

\begin{tabular}{lcl}
\hline & Bone marrow & Blood \\
\hline & $\begin{array}{l}\text { CFU-GM per } \\
2 \times 10^{5} \text { cells } \\
\text { plated }\end{array}$ & $\begin{array}{l}\text { CFU-GM } \\
\text { per } 10^{\circ} \text { cells } \\
\text { plated }\end{array}$ \\
Normal & $117 \pm 8$ & $26 \pm 4$ \\
Recipient & $29 \pm 24$ & $12 \pm 6$ \\
Normal and recipient & $127 \pm 43$ & $33 \pm 9$ \\
Donor & $124 \pm 8$ & - \\
Donor and recipient & $76 \pm 31$ & - \\
\hline
\end{tabular}

forming cells to E-depleted samples before plating. $\mathrm{E}^{+}$rosette forming cells were readded to E-depleted marrow at ratios of $1: 5,1: 2$, or $1: 1$, the mixture was incubated for $1 \mathrm{~h}$ and then cells were plated for CFU-G,M. Data are summarized in Fig. 2. As previously indicated removal of $\mathrm{E}^{+}$rosette-forming cells resulted in an increase in CFU-G,M; readdition of $\mathrm{E}^{+}$cells resulted in a dose-dependent reduction of CFU-G,M. Similar readdition experiments using normal $\mathrm{T}$-depleted bone marrow mononuclear cells and autologous $T$ cells showed no inhibition.

We also studied the effect of $T$ cell depletion on CFU-G,M using a murine monoclonal antibody to the $\mathrm{E}$ rosette receptor (B7) rather than physical techniques. Recipient bone marrow cells were treated with B7 and complement and CFU-G,M enumerated. The efficiency to $T$ cell removal was assessed by testing for residual $\mathrm{E}^{+}$rosette-forming cells, and by indirect immunofluorescence staining using both B7 and 3 unrelated anti-T-antibodies (Leu 1, 2, and 3) reactive with different $T$ cell surface antigens than B7. The latter controls were used to exclude the possibility that $\mathrm{B} 7$ treatment might block $\mathrm{E}^{+}$ rosette formation and $B 7$ reactivity in immunofluorescence without cytotoxicity. Under all three experimental conditions, the proportion of either $\mathrm{E}^{+}$rosette, B7 positive, or Leu 1, 2, or 3 positive cells was $<2 \%$. Nevertheless, in contrast to the effects of $\mathrm{E}^{+}$rosette depletion by physical techniques, antibody treatment had no effect on increasing CFU-G,M (pretreatment, $36 \pm 14$ vs. posttreatment, $31 \pm 7$ ).

Finally, we sought to determine whether this finding of decreased or absent CFU-G,M was specific to the myeloid lineage or affected other hematopoietic stem cells. BFU-E were studied in peripheral blood from 13 normal individuals and 6 recipients. In contrast to the data regarding CFU-G,M, no

Table V. Effect of E-rosette Depletion on CFU-GM

\begin{tabular}{llllll}
\hline & \multicolumn{2}{l}{$\begin{array}{l}\text { Bone marrow } \\
\text { (CFU-GM per } 2 \times 10^{5}\end{array}$} & & \multicolumn{2}{l}{$\begin{array}{l}\text { Blood (CFU-GM per 10 } \\
\text { cells plated) }\end{array}$} \\
\cline { 2 - 3 } & Control & E-Depletion & & Control & E-Depletion \\
\hline Normal & $170 \pm 21$ & $209 \pm 48$ & & - & - \\
1 & $34 \pm 6$ & $142 \pm 13$ & & $9 \pm 2$ & $25 \pm 7$ \\
2 & $30 \pm 7$ & $157 \pm 15$ & & $7 \pm 2$ & $21 \pm 4$ \\
3 & $44 \pm 12$ & $115 \pm 9$ & & $17 \pm 3$ & $29 \pm 6$ \\
\hline
\end{tabular}




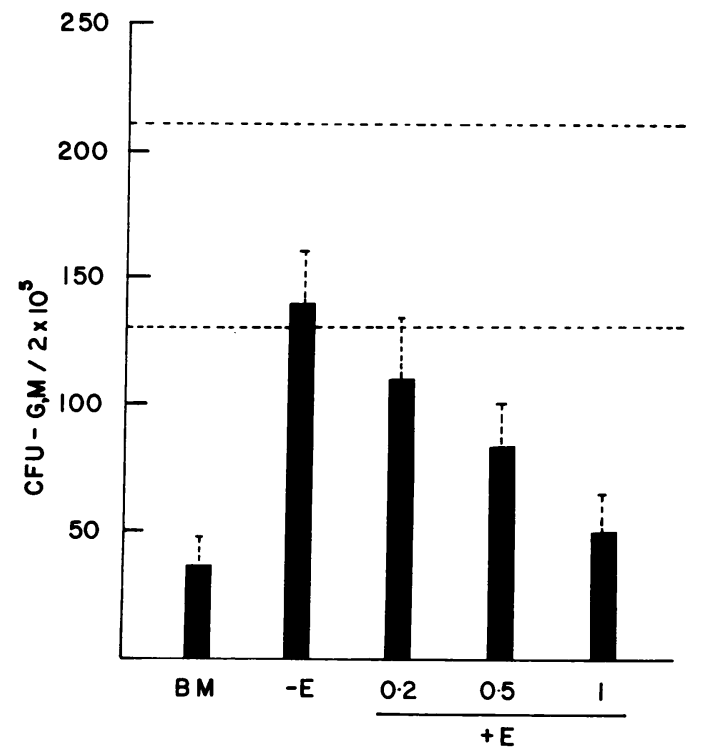

Figure 2. Effect of readdition of autologous E+ cells to E-depleted bone marrow mononuclear cells. BM, recipient bone marrow; $-\mathrm{E}$, $\mathrm{E}^{+}$-depleted; $+\mathrm{E}$, readdition of autologous $\mathrm{E}^{+}$cells at ratios of 0.2 , 0.5 , and 1.0:1. Dashed lines indicate normal range.

significant decrease in BFU-E was observed; $152 / 3 \times 10^{5}$ for controls vs. $155 / 3 \times 10^{5}$ transplant recipients.

\section{Discussion}

Peripheral blood and bone marrow CFU-G,M were absent or markedly reduced in 29 patients studied from 2 mo to $8 \mathrm{yr}$ following apparently successful bone marrow transplantation. Most of these patients had normal levels of circulating neutrophils, normal bone marrow cellularity, and a normal myeloid:erythroid ratio. The reduction in CFU-G,M, was independent of age, sex, underlying diagnosis, conditioning regimen, bone marrow cell dose, and the source of transplanted bone marrow cells. Marked reductions in CFU-G,M were observed in recipients of HLA-identical sibling, genetically identical twin, and autologous bone marrow transplants. The reduction in CFU-G,M was observed as long as 8.5 yr after transplantation and there was no apparent trend to recovery over time.

We studied several potential mechanisms that could account for this disparity between apparently normal granulopoiesis in vivo and markedly decreased or absent CFU-G,M as assayed in vitro. Co-culture of unfractionated or T-enriched recipient peripheral blood or bone marrow mononuclear cells with peripheral blood or bone marrow cells from normal individuals produced no inhibition of normal CFU-G,M. Addition of peripheral blood- or bone marrow-derived mononuclear cells from normals did not reverse the decreased CFU-G,M growth of cells from transplant recipients. Similar results were obtained when serum from recipients was added to CFU-G,M cultures; there was no suppression of normal CFU-G,M growth or correlation of the defect in transplant recipients. However, when recipients (donor-derived) bone marrow cells were cocultured with donor bone marrow cells, a decrease in CFUG,M was observed. Furthermore, the removal of $T$ cells from recipient bone marrow by physical techniques resulted in an increase in CFU-G,M was also noted with $T$ cell depletion.
The marked increase in bone marrow-derived CFU-G,M (32 $\pm 14-138 \pm 36)$ following depletion of $\mathrm{E}^{+}$cells cannot be explained simply by removal of non-CFU-G,M forming cells, since only $15-27 \%$ of the bone marrow mononuclear cells were $\mathrm{E}^{+}$. One would thus expect only a modest increase in CFU-G,M compared with the fourfold increase observed. Furthermore no increase in CFU-G,M was observed when bone marrow cells from controls were similarly treated.

Density centrifugation may have differential effects on CFU-G,M recovery from normal vs. transplant recipient bone marrow mononuclear cells independent of any effect of $T$ cell depletion. As indicated, our $\mathrm{T}$ cell depletion technique required a second density centrifugation to remove contaminating $T$ cells. To avoid potential comfounding of the results by this gradient-related variable, we also analyzed total CFU-G,M recovery pre- and post- $T$ cell depletion in three transplant recipients. $10^{7}$ bone marrow mononuclear cells contained $1.76 \pm 0.6 \times 10^{3}$ (mean \pm SEM) CFU-G,M. Recovery of nucleated cells after $T$ depletion was $7.3 \pm 0.8 \times 10^{6}$. This fraction contained $4.8 \pm 0.6 \times 10^{3} \mathrm{CFU}-\mathrm{G}, \mathrm{M}$, which is equivalent to a plating efficiency of $160 / 2 \times 10^{5}$. These data indicate that the increase in CFU-G,M observed following $T$ cell depletion (Table V) is not the result of selective enrichment for CFUG,M by density centrifugation. These data suggest that these cells actively inhibit CFU-G,M growth in vitro. This observation was further supported by experiments in which readdition of autologous $\mathrm{E}^{+}$cells to E-depleted mononuclear cells resulted in a dose-dependent decrease in CFU-G,M (Fig. 2).

We were concerned that data regarding E-depletion and allogeneic co-culture experiments gave disparate findings, i.e., E-depletion resulted in increase CFU-G,M, whereas no inhibition was observed in co-culture experiments. One possible explanation for the desparity is that the suppressive effect of the $\mathrm{E}^{+}$cells was immunologically specific. In preliminary experiments we co-cultured $\mathrm{E}^{+}$cells from recipients with $\mathrm{E}^{-}$ cells from normals. No inhibition of normal CFU-G,M was observed that confirmed this hypothesis. This is further supported by the data in co-culture experiments utilizing transplant recipients and their donor bone marrow. Following marrow transplantation, the recipients hematopoietic cells are donorderived, genetically identical to the transplant donor. Similar evidence of immunologic restoration of $T$ cell inhibition of hematopoiesis has been reported by others $(17,18)$.

In contrast to the results with $T$ cell removal by physical techniques, treatment of marrow cells with a monoclonal antibody (B7) to the E-rosette receptor and complement had no effect on CFU-G,M. The reason for this disparity is unknown but there are several possible explanations. It is possible that these inhibitory $T$ cells need not be viable to interact with CFU-G,M. More likely is the possibility that B7 or the rabbit complement might react either directly with CFU-G,M or with a critical accessory cell needed for CFUG,M proliferation. Studies to address these questions are in progress.

Data from studies in rodents and dogs receiving bone marrow transplants are consistent with our observations in man of decreased CFU-G,M. For example, Siminovitch et al. (19) reported decreased hematopoietic stem cells (CFU-S) in serially transplanted mice. In secondary transplant recipients, the decrease in CFU-S persisted for up to $50 \mathrm{~d}$; in tertiary recipients the decrease in CFU-S remained depressed indefinitely. Similar data have been reported by others $(20,21)$. 
Hellman and co-workers demonstrated reduced self-replicative capacity of murine CFU-S following serial marrow transplantation (22). They suggested an inverse relationship between differentiative capacity and potential for stem cell self-renewal. A similar mechanism has been suggested by Morley and coworkers in busulfan-treated mice (23). These mice maintain near normal peripheral blood counts and bone marrow cellularity despite marked reductions in committed (CFU-G,M) and pluripotent CFU-S. Based on these data one could hypothesize that after bone marrow transplantation in man there is an increased demand on stem cells for differentiation that takes precedence over the demand for self-renewal leading to progressive stem cell depletion. Boggs and Boggs have suggested that a similar mechanism may be operative in some patients with aplastic anemia (24). Harrison and Astle (25) described the loss of stem cell repopulating ability following transplantation into lethally irradiated mice in a competitive repopulation assay. They found decreased stem cells levels following transplantation by parabiosis or sublethal irradiation. These data imply that it is not the transplant procedure per se that is responsible for the abnormality. Recently, Raghavachar and co-workers reported a similar prolonged decrease in CFU-G,M in dogs that received autologous bone marrow transplant (26).

There have been several preliminary reports of decreased CFU-G,M after bone marrow transplantation in man. Haak and co-workers (27) found decreased CFU-G,M in five of six patients studied $\geq 3$ mo posttransplant including one recipient of a twin transplant (28). These investigators suggested a proliferative defect in CFU-G,M based on studies of shortterm CFU-G,M proliferation in liquid culture. Messner recently observed decreased CFU-G,M in some transplant recipients (personal communication). In contrast to these studies, Atkinson and co-workers (29), Faille et al. reported normal CFUG,M in transplant recipients (30). The number of patients studied was, however, small and most were evaluated $\leq 3$ mo posttransplant. These investigators also used a different technique to isolate mononuclear cells and expressed their data in terms of CFU-G,M per milliliter rather than plating efficiency as was used herein. The time at which the studies are undertaken may be important since Arnold and co-workers reported normal CFU-G,M in the first 3 mo after transplantation followed by decreased levels (31). We avoided studying patients in the early posttransplant period because of inherent errors in quantitating CFU-G,M in patients with decreased bone marrow cellularity. In none of these studies was the mechanism for the decrease in CFU-G,M investigated in detail.

Interestingly, other investigators have reported decreased CFU-G,M in patients with hematologic disorders who did not receive bone marrow transplants. For example, Bacigalupo and co-workers (32) found reduced CFU-G,M in eight patients with severe AA who recovered normal or near-normal blood counts and bone marrow cellularity following immune suppression with high-dose corticosteroids and/or antilymphocyte globulin. Recently, Testa reported decreased CFU-G,M in children with ALL who completed 2-3 yr of maintenance chemotherapy and were in hematologic remission with normal blood counts for several years (33). These patients are of interest since they also appear to have persistent abnormalities of T lymphocyte function. Weiner et al. reported (34) decreased CFU-G,M following intensive chemotherapy of AML. In this instance, the suppression was thought to be related to a macrophagic-like cell. Deschel and co-workers found decreased blood (but not bone marrow) CFU-G,M in patients with acute leukemia in long-term remission (35).

There are several common features within the spectrum of experimental and clinical settings reported to result in decreased levels of stem cells (CFU-S or CFU-G,M) despite normal levels of peripheral blood cells and normal bone marrow cellularity. In most instances, there has been either damage or stress to the bone marrow followed by gradual recovery of normal or near-normal hematopoiesis. Furthermore, several of these settings including busulfan-treated mice, patients with ALL and AA, and human transplant recipients, are also associated with immune abnormalities. Data indicating normal levels of BFU-E suggest that the defect in CFU-G,M is unlikely to be the result of nonspecific myelotoxicity by drugs given posttransplant such as methotrexate or trimethoprim-cotrimoxazole; a conclusion further supported by demonstration of the CFUG,M defect in twins and autotransplant recipients.

The data presented herein suggest that the observed decrease in CFU-G,M in transplant recipients resulted, at least in part, from an abnormal in vitro interaction between CFU-G,M and $\mathrm{E}$ rosette-forming cells. Whether a similar abnormality is operational in vivo is unknown but is suggested by the increased sensitivity of transplant recipients to cytotoxic chemotherapy. Also unknown whether this abnormal interaction is restricted to CFU-G,M or affects other more primitive granulocyte-macrophage progenitor cells, such as CFU-DG or CFU-GEMM. Other cell lines may also be affected. We and others have reported decreased $\mathrm{T}$ lymphocyte progenitor cells (CFU-T) in transplant recipients $(34,36)$. It is hoped that a detailed analysis of the cellular mechanism underlying this apparent disparity between hematopoietic recovery and CFUG,M activity may provide an insight to normal mechanisms of regulation of hematopoiesis.

\section{Acknowledgments}

We thank Capice Moran and Shena Huang-Winston for expert technical assistance, Dr. Winston G. Ho and Dr. Ronald Mitsuyasu for help in obtaining samples for study, and Celene Ushry who typed the manuscript.

This work was supported by grant CA-23175 from the National Cancer Institute and RR-00865 from the National Institutes of Health, U. S. Public Health Service, Department of Health and Human Services. Dr. Champlin is a recipient of a New Investigator Research Award from the National Institute of Arthritis Diabetes, Gastrointestinal and Kidney Disease, National Institutes of Health.

\section{References}

1. Champlin, R., and R. P. Gale. 1984. Role of bone marrow transplantation in the treatment of hematologic malignancies and solid tumors: a critical review of syngeneic, autologous and allogeneic transplantation. Cancer Treat. Rep. 68:145-161.

2. Gale, R. P., W. Ho, S. Feig, R. Champlin, A. Tesler, E. A. Arenson, S. Ladish, L. Young, D. Winston, R. Sparkes, J. Fitchen, M. Territo, G. Sarna, L. Wong, Y. Paik, Y. Bryson, D. Golde, J. Fahey, and M. Cline. 1981. Prevention of graft rejection following bone marrow transplantation. Blood. 57:9-12.

3. Sarna, G. P., S. A. Feig, G. Opelz, L. Young, E. Langdon, G. Jullard, F. Naeim, R. Sparkes, D. Golde, M. Territo, C. Haskell, G. Smith, F. Fawzy, P. Falk, M. Cline, and R. P. Gale. 1977. Bone marrow transplantation with intensive combination-chemotherapyradiation therapy (SCARI) in acute leukemia. Ann. Intern. Med. 86:155-159.

4. Gale, R. P., M. J. Cline, J. L. Fahey, S. Feig, G. Opelz, L. 
Young, M. Territo, D. W. Golde, R. S. Sparkes, N. Naeim, G. Jullard, C. Haskell, F. Fawzy, G. Sarna, and P. Falk. 1976. Bone marrow transplantation in severe aplastic anemia. Lancet. II:921-924.

5. Winston, D. J., R. P. Gale, D. V. Meyer, and L. S. Young. 1976. Infectious complications of human bone marrow transplantation. Medicine (Baltimore). 58:1-32.

6. Winston, D. J., Y. J. Bryson, W. G. Ho, M. C. Territo, D. W. Golde, and R. P. Gale. 1980. Interstitial pneumonia and cytomegalovinus infection after bone marrow transplantation. 1980. In Biology of Bone Marrow Transplantation. R. P. Gale, editor. Academic Press, New York. 83-97.

7. Douer, D., R. E. Champlin, W. G. Ho, G. P. Sarna, J. H. Wells, R. P. Graze, M. J. Cline, and R. P. Gale. 1981. High-dose combinedmodality therapy and autologous bone marrow transplantation in resistant cancer. Am. J. Med. 71:973-976.

8. Sparkes, R., M. L. Crist, R. S. Sparkes, R. P. Gale, and S. A. Feig. 1977. Gene markers in human bone marrow transplantation. Vox Sang. 33:202-206.

9. Boyum, A. 1968. Isolation of mononuclear cells and granulocytes from human blood. Scand. J. Clin. Lab. Invest. 97(Suppl.):77-89.

10. Fitchen, J. H., and M. J. Cline. 1979. Human myeloid progenitor cells expressing HLA antigens. Blood. 53:794-797.

11. Pike, B. L., and W. A. Robinson. 1970. Human bone marrow colony growth in agar-gel. J. Cell. Physiol. 76:77-84.

12. Golde, D. W., S. G. Quan, and M. J. Cline. 1978. Human T lymphocyte cell line producing colony-stimulating activity. Blood. 52:1068-1074.

13. Moretta, L., M. Ferrarini, M. C. Mingari, A. Moretta, and S. R. Webb. 1976. Subpopulations of human T cells identified by receptors for immunoglobulins and mitogen responsiveness. J. Immunol. 117:2171-2174

14. Markey, G. M., H. D. Alexander, T. Morris, and J. Robertson. 1982. A rapid method for identification of surface antigen on fixed cell using monoclonal antibodies. J. Clin. Pathol. 35:1295-1301.

15. Torok-Storb, B. J., E. Sieff, R. Storb, J. Adamson, and E. D. Thomas. 1980. In vitro tests for distinguishing possible immunemediated aplastic anemia from transfusion-induced sensitization. Blood. 55:211-215.

16. Dixon, W. J. 1969. Biomedical computer programs, X-Series. (Suppl., University of California Press, Berkeley).

17. Torok-Storb, B., and J. A. Hansen. 1982. Modulation of in vitro BFU-E growth by normal la-positive $T$ cells is restricted by HLADR. Nature (Lond.). 298:473-474.

18. Lipton, J. M., L. M. Nadler, G. P. Canellos, M. Kudisch, C. S. Reiss, and D. G. Nathan. 1983. Evidence for genetic restriction in the suppression of erythropoiesis by a unique subset of $\mathrm{T}$ lymphocytes in man. J. Clin. Invest. 72:694-706.

19. Siminovitch, L., J. E. Till, and E. A. McCulloch. 1964. Decline in colony-forming ability of marrow cells subjected to serial transplantation into irradiated mice. J. Cell Comp. Physiol. 64:23-31.

20. Vos, D., and M. J. A. S. Dolmans. 1972. Self-renewal of colony forming units (CFU) in serial bone marrow transplantation experiments. Cell Tissue Kinet. 5:371-385.

21. Harrison, D. E. 1972. Normal function of transplanted mouse erythrocyte precursors for $\mathbf{2 1}$ months beyond donor life spans. Nature (Lond.). 237:220-222.

22. Hellman, S., L. W. Botnick, E. C. Hannon, and R. M. Vigneulle. 1978. Proliferative capacity of murine hematopoietic stem cells. Proc. Natl. Acad. Sci. USA. 75:490-494.

23. Morley, A., K. Trainor, and J. Blake. 1975. A primary stem cell lesion in experimental chronic hypoplastic marrow failure. Blood. 45:681-688.

24. Boggs, D. R., and S. S. Boggs. 1978. Possible pathogenic mechanisms in aplastic anemia. Transplant. Proc. 10:125-130.

25. Harrison, D. E., and C. M. Astla. 1982. Loss of stem cell repopulating ability upon transplantation. J. Exp. Med. 156:17671779.

26. Raghavachar, A., O. Prummer, T. M. Fliedner, and K. H. Steinbach. 1983. Functional studies on myeloid progenitor cell reconstitution after autologous stem cell transplantation. Exp. Hematol. 11(Suppl. 14):71.

27. Haak, H. L., H. M. Goselink, W. Veenhof, S. PellinkhoffStadelmann, J. K. Kleiverda, and J. te Velde. 1981. Acquired aplastic anemia in adults. I. V. Histological and CFU studies in transplanted and non-transplanted patients. Scand. J. Hematol. 19:159-171.

28. Barrett, A. J., and J. Adams. 1981. A proliferative defect of human bone marrow after transplantation. Br. J. Haematol. 49:159164.

29. Atkinson, K., S. Norrie, P. Chan, and J. Biggs. 1982. Bone marrow cellularity and blood and marrow myeloid and erythroid stem cell colony growth during the first three months after allogeneic marrow transplantation for severe aplastic anemia or acute leukemia. Exp. Hematol. 10(Suppl. 11):34.

30. Faile, A., D. Maraninchi, E. Gluckman, A. Darergie, N. Balitrand, F. Ketels, and C. Dresch. 1981. Granulocyte progenitor compartment after allogeneic bone marrow grafts. Scand. J. Haematol. 26:202-214.

31. Arnold, R., W. Heit, H. Heimpel, N. Frickhofen, T. Schmeiser, and $B$. Kubanek. 1982. The reconstitution of hematopoietic precursors after bone marrow transplantation. Exp. Hematol. 10(Suppl. 10):7982.

32. Bacigalupo, A., M. Podesta, M. D. Mingari, L. Moretta, M. T. V. Ling, and A. Marmont. 1980. Immune suppression of hematopoiesis in aplastic anemia: Activity of $\mathrm{T}$ and gamma lymphocytes. J. Immunol. 125:1449-1453.

33. Layward, L., R. J. LeVinsky, and M. Butler. 1981. Long-term abnormalities in $\mathrm{T}$ and $\mathrm{B}$ lymphocyte function in children following treatment for acute lymphoblastic leukemia. Br. J. Haematol. 49:251258.

34. Weiner, R. S., D. J. Oblon, and M. A. Gross. 1983. Stem cell defects after intensive cytoreductive therapy for AML. Exp. Hematol. 11(Suppl. 14):41.

35. Peschel, C., G. Konwinka, D. Geissler, B. Tomaschek, K. Grumewald, H. Huber, R. Odevic, and H. Braumsteiner. 1983. Studies of myelopoiesis in vitro on blood and bone marrow cells of patients with acute leukemia in long-term remission. Leukemia Res. 7:397406.

36. Gale, R. P., S. Li, and J. H. Fitchen. 1982. Hematopoietic reconstitution following bone marrow transplantation. Exp. Hematol. 10(Suppl. 11):31. 